\title{
http://bjas.journals.ekb.eg
}

\section{Surgical Management for Resistant Lateral Epicondylitis}

A.H.Adawy, A.S.Rizk, E.A.Tabl and E.H.Helal

Orthopedic Surgery Dept., Faculty of Medicine, Benha Univ., Benha, Egypt

E-Mail:Amr20@gmail.com

\begin{abstract}
$5: 10 \%$ of cases of lateral epicodylitis are resistant to conservative treatment and need surgical intervention.The purpose of this study was to evaluate the clinical outcomes of Modified Nirschl techniques for treatment of tennis elbow .An Prospective case arrangement contemplate might have been intended between february 2019 What's more january 2020 including 20 patients from outpatient facility from claiming Benha school healing center enduring starting with safe horizontal epicondylitis. Nitty gritty therapeutic history, clinical examination and PRTEE score connected will every one patients pre and post-operatively. There were 8 female What's more 12 male patients in the ponder. The mean span about indications in the recent past surgery might have been 14.3 months. Those Normal span from claiming catch up might have been 28 months. We found that the changed Nirschl system need swaying brings about administration of horizontal epicondylitis clinched alongside (95\%) of instances for An imply about 4 weeks period should profit on typical exercises Furthermore 15. 3 weeks will resume overwhelming exercises without agony. Those aggregate PRTEE score moved forward from a mean for 67 focuses to a intend of 6 focuses postoperatively. Those altered Nirschl system allotments almost equivalent comes about for different methods ,although those patients profit to their exercises after the fact over the opposite strategies. Additionally this strategy need favorable element of beneficial visualization of the entire degenerated tissues guaranteeing flawless debridement. Therefore, we recommended this choice following fizzled preservationist oversaw economy of horizontal epicondylitis.
\end{abstract}

Keywords : Lateral epicondylitis, Surgery, Release, Modified Nirschl, Tennis elbow.

\section{Introduction}

Agony from those parallel angle of the elbow might have been 1st portrayed Previously, 1873, What's more need from that point forward been provided for separate names for example, tennis elbow, parallel epicondylitis, epicondylosis $[1,2]$. Those fundamental objections done horizontal epicondylitis need aid torment Furthermore diminished grip quality making critical inability over Every day exercises [3]. It influences 1-3\% for populace in the age class for 40-60 quite some time [4]The essential drivers about epicondylitis are the contractile overloads that chronically anxiety those tendon close to its connection on the horizontal epicondyle for humerus in tedium upper limit exercises for example, substantial lifting ,computer use, compelling lower arm supination Also pronation, What's more tedium vibration [5]. Over $75 \%$ for cases, those predominant side may be influenced [6]. The etiology from claiming tedeum will be not known, Yet it will be viewed as will be a abuse damage [7]. This tissue reaction need been translated Concerning illustration aggravation thus called horizontal epicondylitis. In any case, there would no indications of a prostaglandin interceded aggravation [8].

The abuse makes combined micro trauma that weakens the structural, vascular components of the tendon Also weariness split of the tenocytes till the capacity should repair shed will be overwhelmed[9]. In the constant stage there will be a with the goal called neurogenic aggravation for vasodilatation[10]. Nirschl(1992) bring depicted those minute presence Similarly as a degenerative transform with thick populaces of fibroblasts, vascular hyperplasia (angiofibroblastic hyperplasia) Furthermore confused collagen without indications of aggravation (angiofibroblastictendinosis ) [11]. Perceptible manifestation of the ECRB-tendon will be dull, grey, friable Also oedematous [12]. Therefore, those sake epicondylitis doesn't appear right so it is known as angiofibroblastictendinosis [13]. Tendinosis bring demonstrated tangible What's more thoughtful nerves in the profound side of the tendon [14]. Immunoreactivity to the neurotransmitters Likewise substance $p$,glutamate What's more calcitonin gene-related peptide (CGRP), need been Additionally showed clinched alongside (ERCB) [15]. Different tendinopathies (Achilles Also patella vulgata tendon) bring demonstrated An neighborhood catecholamine generation inside nonneural phones ,and so playing a part in the regulation from claiming blood flow, neighborhood progressions in the tissue What's more ache [16]. Acetylcholine need been found with be generated Toward non-neural units On tendons for patients suffice from patella vulgata and Achilles tendinopathies [17]. It will be not referred to Assuming that such a nearby catecholamine or acetylcholine preparation may be introduce for tedeum [18].

Preservationist medicines incorporate NSAIDs, steroid injection, utilitarian support Furthermore manipulative medicine [19]. Practically patients react with nonoperative medication [20]; however, surgical medication is fundamental clinched alongside $4 \%-11 \%$ about patients [20]. Different agent systems need been portrayed including open president release, percutaneous arrival Furthermore arthroscopic arrival. Those fundamental part from claiming constantly on methods will be debridement of the obsessive ECRB tendon tissue, Also decortication of the horizontal epicondyle [21]. Those best surgical medication is not known. Those impediments of open ECRB arrival incorporate late profit to fill in Also brandishing, An danger from claiming posterolateral precariousness of the elbow because of parallel ligament intricate injuries, and the structuring of neuroma then afterward surgery [22]. Percutaneous extensor tenotomy could incorporates those 
hazard from claiming repeat. For respect to arthroscopic ECRB release, it may be troublesome to suture the cracked ECRB on keep away from those danger about harm of the parallel insurance ligament [23].

\section{Aim of the work}

To study the role of Modified Nirschl Procedure in treatment of resistant lateral epicondylitis .

\section{Patients and methods}

Then afterward Regard of the neighborhood regulate moral council about Benha college clinic What's more after bringing a composed assent from those patients. This Prospective case arrangement consider might have been performed Eventually Tom's perusing selecting 20 patients starting with the outpatient facility from claiming Benha school healing facility in the period between february 2019 and january 2020. The Incorporation criteria were skeletally develop patients for safe horizontal epicondylitis inert to every last one of accessible nonsurgical measures to no less than 3 months. Avoidance criteria were, systemic issue Likewise (Coagulation disorders, dm Also rheumatoid arthritis),local abandon as past surgery, contamination ,previous crack alternately neighborhood harm. Additionally On Skletally adolescent patients, arthritis Also neurological abnormalities. All hopefuls were subjected on point by point restorative history taking ,Clinical examination What's more patient-related tennis elbow assessment PRTEE score .We used the modified Nirschl technique using a $3 \mathrm{~cm}$ skin incision on lateral epicondyle then reaching ECRB in gap between ECRL and EC muscle. Then we excised the dead tissue and drilled the bone beneath it. Finally we repaired ECRL, EC and skin and put the patient in arm sling.. Postoperatively, the patients were re-assed post-operatively Toward utilizing the (PRTEE) scores and the A ones were utilized for dissection Also we resumed catch up. Two sorts about facts were carried 1-Descriptive detail to which Quantitative information were communicated for Mean, standard deviation of the mean $(\mathrm{x} \pm \mathrm{SD})$, Also standard lapse (SE) ,2- Qualitative information which were communicated over amount (frequency), Furthermore percent (\%).

Finally, information were investigated utilizing SPSS 18 (Statistical one bundle to social Science) on arrange Furthermore statistically examine gathered information. V. 16. Qualitative information exhibited as numbers. P (probability) esteem from claiming $>0$. 05 implies inconsequential contrasts. $\mathrm{P}-$ value $<0.05$ recognized statistically noteworthy. $\mathrm{P}-$ value $<0.01$ recognized Exceptionally critical.

\section{Results}

Twenty patients (14 male What's more 6 female) were incorporated in this investigation. Those imply agdistis In the run through for surgery might have been 37. 3years (ranged from 20 should 60). Those Normal span of preoperative side effects might have been 14 . 3 months. The greater part patients come back on common exercises inside a normal time period for 15 . 3 weeks (ranged starting with 12-20 weeks) Table( ). The sum patients required past preservationist medicine with no triumph should mitigate their indications. Those mean span for post-operative catch up might have been 28 weeks (16 should 40 weeks). Every one patients accounted for change for indications post-operatively in distinctive degrees. Those mean PRTEE score of ache enhanced from a pre-operative intend from claiming 67 should 6 In 16 weeks post-operative as for Table(1),Fig(1). We need gotten PTREE scores Throughout the last visit that these scores need aid autonomous from those taking after parameters: age, sexual orientation span for indications. No real difficulties happened then afterward surgery. Toward those last visit, no tolerant obliged further surgery alternately infusion then afterward surgery.

Table (1) pre and post-operative PRTEE score among studied patients .

\begin{tabular}{lccc}
\hline & PRTEE score & Test of significant & P Value \\
\hline Preoperative & $67.40 \pm 12.51$ & Paired t test & \\
Mean \pm SD & $45-89$ & & \\
Range & 67 & 23.20 & $\leq 0.001$ \\
Median & & & \\
Postoperative 16 weeks & $5.90 \pm 1.83$ & \\
Mean \pm SD & $3-9$ & \\
Range & 6 & & \\
Median & & & \\
\hline
\end{tabular}




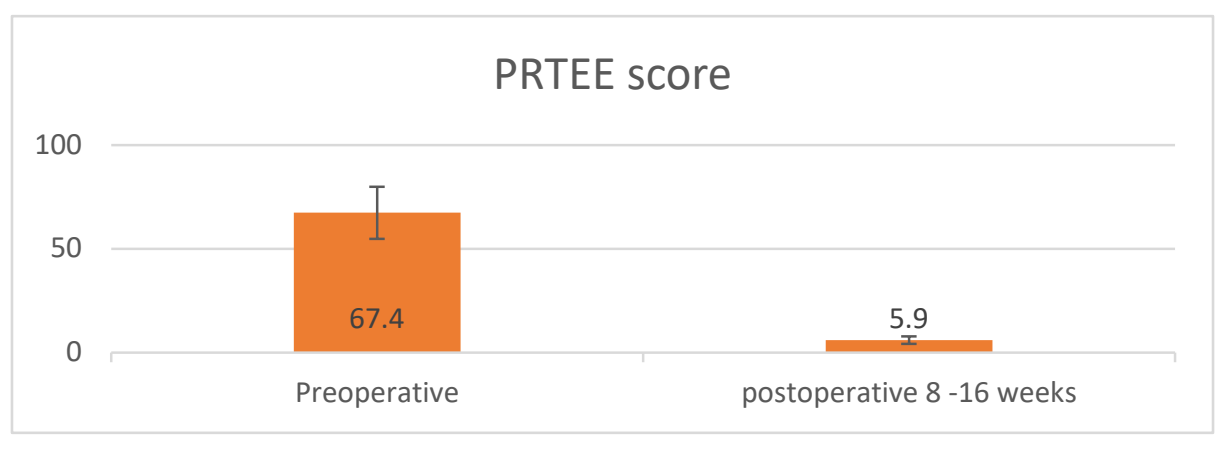

Fig (1) pre and post-operative PRTEE score among studied patients.

\section{Discussion}

Horizontal epicondylitis might have been primary portrayed Eventually Tom's perusing Runge done 1873 Likewise a heavenly body about ache for delicacy In those parallel epicondyle, for resisted wrist dorsiflexion, What's more for latent wrist flexion. Horizontal epicondylitis would frequently all the treated to more stupendous over $90 \%$ of patients for preservationist measures ,such as rest, medication, immobilization, physical therapy, What's more neighborhood steroid infusion. The rate from claiming surgery to safe situations fluctuating starting with 0 on $22 \%$. (24). Horizontal epicondylitis need a lot of people surgical choices for medicine including: open ECRB release, percutaneous extensor tenotomy What's more arthroscopic ECRB. These methods not vary in the idea that those primary site from claiming obsessive progressions is those ECRB root. These transforms incorporate perceptible alternately minute mournful, scar tissue, vascular granulation Also fibroblastic intrusion once light microscopy, so the part of surgery is debridement of the degenerated tissues prompting helter skelter level of change and negligible rate of repeat for symptoms, something like that this may be those primary variable for Inclination offers Inclination the middle of diverse surgical systems which need aid almost rise to in short term utilitarian results(25). We depend for our proposal on the altered Nirschl system. This method includes arrival of the extensor aponeurosis ,debridement of the ECRB tendon,drilling the horizontal epicondyle Also At long last repair shed of the ECRL of the extensor aponeurosis [24].

Our ponder depicts an ordinary assembly about patients with a imply agdistis at the the long run about surgery about 37 . 3years (ranged starting with 20 will $60)$. What added up to 20 patients (14 men and 6 women) were included for long-standing indications not reacting on nonoperative modalities of medication with 14. 3months Normal span of preoperative manifestations. The mean catch up period might have been 28 weeks (16:40 weeks) postoperatively. The outcomes for this examine need aid swaying. 95\% patients attained an elbow that might have been totally free of torment during last catch up. About the sum patients came back with typical exercises inside a normal occasion when 5 weeks Furthermore return to full exercises What's more fill in toward period from claiming 15. 3 weeks (ranged starting with 12-20 weeks). The intend PRTEE score PRTEE moved forward starting with 67. 4preoperatively on 5. 9 focuses post-operatively. No major difficulties happened on whatever a standout amongst chose patients but two patients need wound contamination Also approached with change of the antimicrobial [26]. At those last visit, no tolerant required further surgery or infusion. Thereabouts this system gives a compelling straightforward technique, with a little entry point, insignificant difficulties and easier rate about repeat of indications over that of the percutaneous methodology due to shameful debridement about ECRB to percutaneous arrival which necessities useful knowledge should make carried out superbly Concerning illustration it may be self-evident in the outcomes of a paper finished once a amendment surgery assessing 34 patients (35 elbows) who Awhile ago needed percutaneous surgery to horizontal epicondylitis without alleviation. Done seven patients, the pathologic ECRB tissue might have been incompletely excised, Also done 27 patients, those ECRB might have been not tended to in the least [27]. Our outcomes need aid About equivalent to these from claiming investigations carried out utilizing altered Nirscl technobabble as the examine carried out by Hohmann done 1933 for the same method recording 97\% change Previously, side effects for $85 \%$ from claiming patients completely came back will worth of effort without ache [28]. Those hindrance of the changed Nirschl method may be that those time necessary with return should fill in may be more drawn out over that On other methods. This may be clear Previously, An investigation carried out by who compared those percutaneous method with the open technobabble to 2004 On an aggregation about 22 patients who underwent the open system Also 23 patients who were dealt with for percutaneous method. Patients came back on fill in then afterward 2 weeks in the percutaneous bunch versus 15 weeks in the open surgery group[29]. Those disservice of the percutaneous discharge will be that it doesn't permit useful visualization of the entire degenerated tissues prompting ECRB inadequate debridement thus providing for secondary rate for repeat from claiming indications.

Arthroscopic discharge for horizontal epicondylitis need the playing point from claiming finish intra- 
articular visualization, less obtrusive technique, early exchange should typical exercises. An investigation finished Eventually Tom's perusing with respect to 54 patients underwent open discharge of the ECRB tendon and 33 patients worked arthroscopically. There might have been no critical distinction in the practical outcomes between the two Assemblies. However, the patients in the arthroscopic bunch were capable to profit to worth of effort prior. [30]. The limits of the altered Nirschl methodology incorporate late profit on fill in What's more wearing exercises, An danger from claiming posterolateral unsteadiness of the elbow Also danger shaping for neuroma following surgery. Overall, it is accepted that this system gives a successful medication choice. Its outcomes need aid in the range about other methods and the Choice of the system Eventually Tom's perusing the specialist returns should as much encounter and the accessible instruments until the three real methods need almost equivalent comes about. Done addition, it is a generally straightforward procedure, with low morbidity, were figured out how effectively with insignificant entry point system under general anesthesia and providing for great effects for patients for parallel epicondylitis, which were safe on long haul preservationist medicines.

\section{Conclusion}

The results obtained in our study supports that Modified Nirschl Procedure is an excellent surgical procedure for treatment of resistant lateral epicondylitis and has nearly equal results and longstanding improvement without regression of symptoms . Patients had no complications with this procedure.The limitation of this study was to compare modified Nirschl with other procedures.Further studies are required to establish this finding.

\section{References}

[1] R. Shiri, E .Viikari-juntura,Varonen Hand Heliovaara, prevalance and determinants of lateral and medialepicondylitispopulation study A.M J Epidemiology,Vol.146(11), PP.1065-1076, 2006.

[2] E .Allander,Prevalence, incidence, and remission rates of some common rheumatic diseases or syndromes. Scand J Rheumatol, Vol.3(3), PP.14553, 1974.

[3] E.R. Dorf,A.B. Chhabra,S.R .Golish,J.L. McGinty,Effect of elbow position on grip strength in the evaluation of lateral epicondylitis. J Hand Surg Am, Vol.32(6), PP.882-6, 2007.

[4] H.W. Gruchow,D. Pelletier,An epidemiologic study of tennis elbow Incidence, recurrence, and effectiveness of prevention strategies. Am J Sports Med, Vol.7(4), PP.234-8, 1979.

[5] B.S. Kraushaar,R.P. Nirschl,Tendinosis of the elbow (tennis elbow)Clinical features and findings of histological, immunohistochemical, and electron microscopy studies. J Bone Joint Surg Am,Vol.81(2), PP.259-78, 1999.
[6] R.P. Nirschl,E.S .Ashman,"Major HP. Lawn-tennis elbow. Br Med J. 1883;2(2):557 Tennis elbow tendinosis (epicondylitis)Instr Course Lect, Vol. 53, PP. 587-98, 2004.

[7] L. Jozsa,M. Lehto,M. Kvist,J.B. Alint,A. Reffy,A Alteration in dry mass content of collagen fibers in degeneration tendinopathy and tendon rupture matrix,Vol. (2)140, PP.146, 1989.

[8] 1.R. Nirsch,Patterns of failed healing in tendon injury Sports-induced inflammation clin basic sci con, Vol.5(14) ,PP.577-585, 1990.

[9] L. Jozsa, M. Lehto,M. Kvist,J.B. Balint,A. Reffy,,A Alteration in dry mass content of collagen fibers in degeneration tendinopathy and tendon rupture matrix, Vol. (2)169, PP.172, 1989.

[10] R.P. Nirschl,"Elbow tendinosis/tennis elbow". Clin Sports Med, Vol.4, PP.851-70, 1992.

[11]W. Regan,R. Coonrad,B.F. Morrey, Microscopic histopathology of chronic refractory lateral epicondylitis, American Journal of Sports Medicine,Vol. 20, PP. 746-749, 1992.

[12] R.P. Nirschl, Elbow tendinosis/tennis elbow.Clin Sports Med, Vol.11(4), PP.851-70, 1992.

[13]B.W. Weinberg,J.L. Cook, K. Gisslen,H. Alfredson,Lateral epicondylitis pathology page,Vol.65, PP.123-129, 2005.

[14]P. Danielson,H. Alfredson,S. Forsgren,Immunohistochemical and histochemical findings favoring the occurrence of autocrine/paracrine as well as nerve-related cholinergic effects in chronic painful patellar tendon tendinosis. Microsc Res Tech, Vol.69, PP.808-819, 2006.

[15]H. Alfredson,L. Ohberg,Neovascul-arisation in chronic painful patellar tendinosis-promising results after sclerosingneovessels outside the tendon challenge the need for surgery. Knee Sports TraumatolArthrosc, Vol.13, PP.74-80, 2005.

[16]D. Bjur, P .Danielson, $H$.Alfredson,S .Forsgren,Presence of a non-neuronal cholinergic system and occurrence of up- and down-regulation in expression of M2 muscarinic acetylcholine receptors: new aspects of importance regarding Achilles tendon tendinosis (tendinopathy). Cell Tissue Res, Vol. 331,PP.385-400, 2008.

[17]P. Danielson, G .Andersson, $\mathrm{H}$.Alfredson,S. Forsgren,Extensive expression of markers for acetylcholine synthesis and of M2 receptors in tenocytes in therapy-resistant chronic painful patellar tendon tendinosis - a pilot study. Life Sci, Vol.80, PP.2235-2238, 2007.

[18]L. Jozsa, M. Lehto,M. Kvist,J.B. Balint,A Alteration in dry mass content of collagen fibers in degeneration tendinopathy and tendon rupture matrix, Vol. (2)151, PP.153, 1989.

[19]H. Labelle,R .Guibert,J .Joncas,N .Newman,M. Fallaha,Lack of scientific evidence for the treatment of lateral epicondylitis of the elbow. An attempted meta-analysis. J Bone Joint Surg Br, Vol.74(5), PP.646-51, 1992. 
[20] R.W. Coonrad,W.R. Hooper,Tennis elbow:its course, natural history, conservative and surgical management. J Bone Joint Surg Am, Vol.55(6), PP.1177-82, 1973.

[21]R. Nirschl,Patterns of failed healing in tendon injury. In: Leadbetter W., Buckwalter, J, Gordon S (eds) Sports-induced Inflammation, American Academy of Orthopaedic Surgeons, Illinois, Vol.32, PP. 577-585, 1989.

[22] R. Inhyeo, C .Chaei,S.B. Gu,K.B. Wo,Arthroscopic treatment of the refractory lateral epicondylitis and associated synovitis. J Shoulder Elbow Soc, Vol.5(2), PP.86-7, 2005.

[23] S.J. Kim,B.M. Park,K.S. Oh,Arthroscopic treatment of lateral epicondylitis. J Korean Orthop Sports Med, Vol.6(2), PP.105-9, 2007.

[24] Y. Marvin,M.R. Safran,K. Marc,Surgical Treatment of Lateral Epicondylitis: A Systematic Review, Vol.54, PP. 85-89, 2005.

[25]25.CochraneRachelle Buchbinder,V. Renea,R.V. Johnston,Reviews matching surgeries for tennis elbow Surgery for lateral elbow pain, Vol. 11 (12), PP. 201-205,2019.
[26]H.Stuart, M.D. Baumgard,R .Donald,M.D. Schwartz,First Published July 1, .Percutaneous release of the epicondylar muscles for humeral epicondylitis, Vol.28, PP.25-36, 1982 .

[27]P.D. Dunkow,M. Jatti,B.N. Muddu,A comparison of open and percutaneous techniques in the surgical treatment of tennis elbow. J Bone Joint Surg Br, Vol.86, PP.701-704, 2004.

[28]G. Hohmann,Das, Wesen, und behandlung des sogenannten tennis ellenbogens Munch Med Wschr,Vol. 80, PP. 250-4,1933.

[29] J .Leppilahti,T .Raatikainen,T. Pienimäki,A. Hänninen,P. Jalovaara,Surgical treatment of resistant tennis elbow. A prospective, randomized study comparing decompression of the posterior interosseous nerve and lengthening of the tendon of the extensor carpi radialisbrevis muscle. Arch Orthop Trauma Surg, Vol.121(6), PP.329-32, 2001.

[30] R.E. Peart, S.S. Strickler,K.M. Schweitzer, Lateral epicondylitis:a comparative study of open and arthroscopic lateral release. Am J Orthop (Belle Mead NJ), Vol.33(11), PP.565-7, 2004. 